\title{
Review on the Impact of Gap Years on Career Development
}

\author{
Tian Guomei ${ }^{1, a, *}$, Ran Wei ${ }^{1, b}$ \\ ${ }^{1}$ School of Business, Sichuan University, Chengdu 610000, China \\ a tiangmfree@163.com, ${ }^{\mathrm{b}}$ 18328006007@163.com \\ *corresponding author
}

Keywords: Gap year, Career development, Employability.

\begin{abstract}
Gap years means that individuals leave formal learning, training or work places to have a pause or a rest during a period of 3-24 months, which has been an obvious feature of the career development in 21st century. While researches on the definition and impact of gap years is far from enough, we aim to review on different types of gap years, the motivation to participate in gap years, its influence on career development, give some possible directions for future research in this last section.
\end{abstract}

\section{Introduction}

Gap years originated in the waves of hippies in 1860s, which mean young people travel abroad, participate in volunteer activity or paid work for a period of time (Simpson, 2005). Jones (2004) believes that gap years is not limited to traveling, volunteer activities or working in companies and he gives a broad definition of gap year: individuals leave formal learning, training or work places to have a pause or a rest during a period of 3-24 months. Nowadays, the universal existence of gap years has become a prominent feature of career development. In a survey about 2000 employees abroad, 1/7 of participants have left their workplaces for gap year practice, and more than $75 \%$ of them are considering doing so (YouGov, poll, 2004). In 2012, an investigation conducted by Sina and EF indicated that $73.3 \%$ of young people wanted to experience "gap years".

The current domestic researches on gap year focuses on this tourism phenomenon (Pearce, 2015), its impact on international culture communication, youth socialization or individualization process, however its impact on career development is overlooked by researchers. Chinese scholar Mao (2015) studied gap year in China and believed that most of practitioners of gap years in China are college graduates or young professionals, who are going to work or have been working for some years, the influence of gap years on career development cannot be ignored. In this paper, we aim to review on different types of gap years, the motivation to participate in gap years, its impact on the career development of individuals and give some possible directions for future research.

\section{The Definition and Characteristics of Gap Year}

At first, gap years refers to the practice during the transition from high school to college or the transformation process in young adults (King, 2011). The transition to college is a meaningful emotional experience for young people who deem gap year as a management of their early years of institutional transition to adulthood (Bagnoli, 2009). As time going on, the definition of gap year has changed. Gap year is not limited to travel, participate in volunteer activities, but includes various other projects or activities, such as factory practice. It is considered as a kind of career breaks and a way to increase the academic and career chips, because it can intensify resumes and is of beneficial to leaning and job-hunting.

In China, most participants of gap years are adults. Some scholars have conducted a survey of 103 gap year practitioners, only 19 of them are college graduates who have enough disposable time to participate in gap year before working and 2/3 of them are conducting career pause, a pause between 
two jobs. The key reason might be that gap year is exclusive, unique and class constraint, not everyone can participate in (Simpson,2005). The cost is also an important restraining factor, students from low-class families may work during this time to raise education tuitions.

There are mainly two classifications of gap years practice. Holmlund (2008) analyzed the effect of five different gap year activities: increasing skills, waiting for a better admission chance, learning interesting things; leisure, work (paid or volunteer) (Holmlund, 2008). From a policy perspective, Jones (2004) summarized six common gap year activities: work (paid or volunteer), learning, travel (organized or independent) and leisure. He believes that the distinction between structured and unstructured activities is whether it is planned or has clear directions.

\section{The Motivation of Participating in Gap Year Practice}

In 1980s, gap year practice is relatively rare, but in 1990s, it greatly increased (Jones, 2004). Some organizations estimate that about 250 thousand young people in the UK participate in gap year every year, although it is difficult to confirm whether the data is accurate. From the perspective of informal estimation, it is certain that there are at least 50 thousand young people in the UK participated in gap year every year (data from The Year Out Group 2003; Gap Year.com 2003). The reason why gap year is so widespread and individuals' motivation to participate in gap year has also received wide attention.

The motivation to participate in gap year is different from person to person. Common reasons are: 1) to get a break from the normal work or study and broaden their horizon (key reason); 2) experience different ethnic and cultural environment to obtain survival skills; 3) enrich resume to get higher education opportunities or increase the possibility of being employed; 4) make money; 5) make contributions to the society; 6) help others; 7) religious beliefs; 8) to meet the challenges; 9) looking for fun. Participants of gap year want to do more things during this time to make better use of it (Jones, 2004). Because of their personal responsibility, young practitioners can make full use of gap year and perform better (Snee, 2015). The motivation to participate in volunteer work varies, while the tendency of altruism is one of the main reasons (Gaskin,1998). They participate in gap years to understand themselves better $\mathrm{n}$ a complex social environment (Jones, 2004). Chinese scholar Wu (2015) organized relative literature on the motivation to participate in gap year with the push and pull model by Dann (1977), push power comes from psychological factors and pull power comes from marketing factors. Between the forces of pulling and pushing, there are some forces that connect to stimulate certain behaviors (Pearce, 2015), as shown in Figure 1

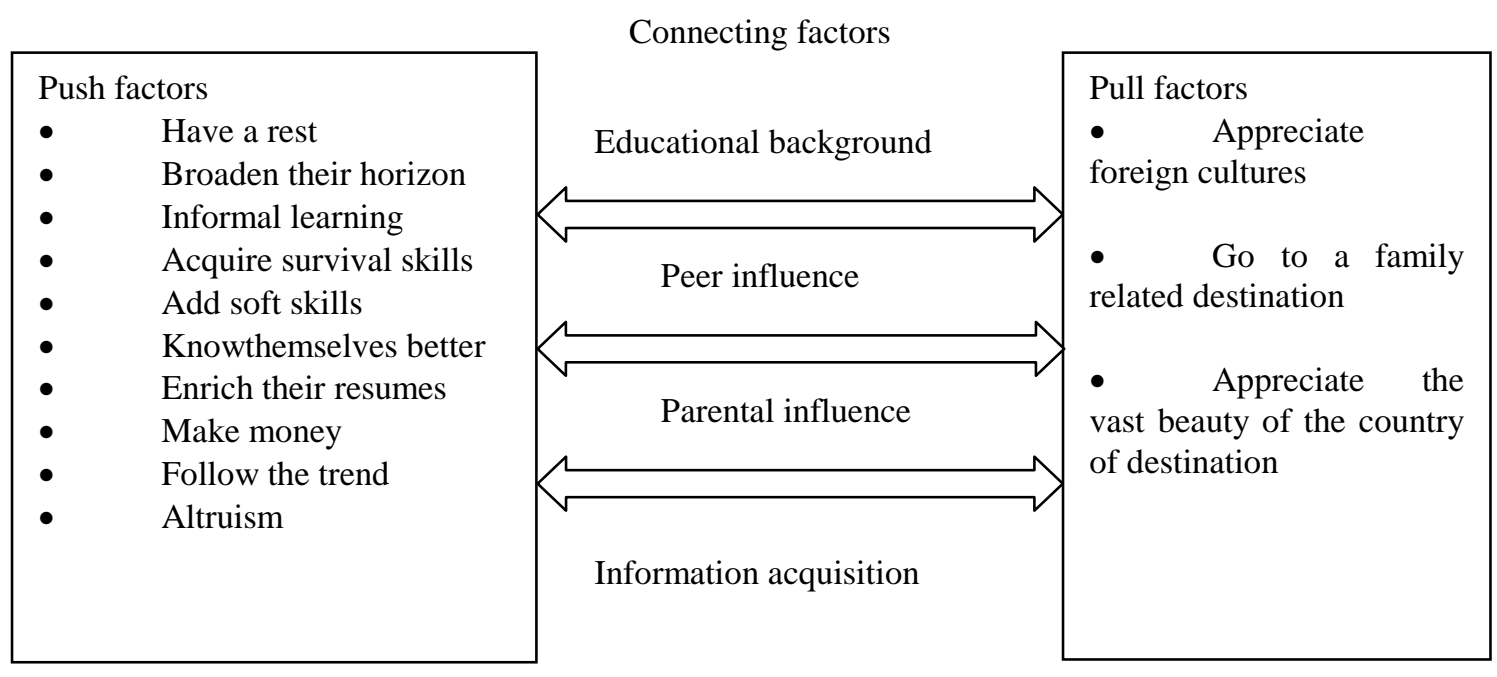

Figure 1 the push-pull model of the motivation of gap year practice 
Although the "push- pull" model is not a formal motivation model in academic terms, it can be useful for organizing different motivations in different fields. In China, the push factors of gap year are same as the main motivations of traveling, and reflect deep Chinese culture situations. Compared with Western gap year participants, Chinese participants have less motivation to enjoy, but more motivation to choose activities and places (Pearce, 2015).

\section{The Influence of Gap Year on Career Development}

\subsection{The Influence of Gap Year on Employability}

Employability refers to the ability to maintain high work efficiency and respond to work changes in time (Xie Jinyu, 2005). The purpose of studying employability is to develop and enhance personal potential and to help them better prepared for their career development. It has been confirmed that gap years is of great importance to enhance employability.

Gap years practice is a way to learn and help young people grow and mature, focusing on developing valuable personal qualities during this transition periods. Individuals usually explore different career paths and opportunities during this time (Johan, 2009). The implementation of gap year has three main advantages: for participants, for employers and external society, which are difficult to measure. Personal benefits: 1) Improving the learning performance; 2) enhancing the employability or increasing the 3) developing skills and qualifications; 4) developing survival skills; 5) developing social value; 6) reducing the possibility of being fired from education, training and employment in the future (Jones, 2004). From the perspective of employability, the current research focuses on increasing the opportunities of being employed. But the research the impact on long-term career development of practitioners is far from enough.

It has been confirmed that gap years can help participants become more mature and independent. It can also help participants acquire soft skills and cultural capital which is needed in the modern work world (Coetzee, 2010). It is also help participants better adapt to the work world and improve their personal status (King, 2011), and ultimately enhance their employability at work (Heath, 2007). Attractive personal qualities are key to success in flexible work and organizational forms, and that's an advantage when graduates looking for a job (Brown, 2003). Obviously, compared with classmates, gap year participants can also show their talents when hunting for a job because this special experience makes them different from their peers (Lyons, 2012). Lyons (2012) also pointed out that many people find their own career path through gap years practice. Most gap year participants believed that is a process of looking for freedom and self-discovery, which broadens their horizons, helps them to realize they want and find the occupation which fits their interest (Cremin, 2012).

It is generally believed that young people's participation in volunteer work and other forms of gap year activities are beneficial to both individuals and society. The British Millenniun volunteers project found that $84 \%$ of participants had increased their self-confidence through this practice. Studies have shown that young people who participate in volunteer and community work in schools generally perform better on tests. When paid work and volunteer work is realized, it is also considered to be helpful to the community and society (Jones, 2004).

\subsection{The Influence of Gap Year on Job-hunting}

Academic credentials are no longer a guarantee of success, and college students must seek other ways to gain advantages, including developing appropriate "personalized travel" to gain communication skills and personality traits that are favored by employers (King, 2011). Traveling to the third world is also a cultural capital that allows practitioners to present to their peers and employers(Simpson,2005). Practitioners are trying to make better use of gap year practice to get a better job. Mostly everyone think this experience is worthwhile and nobody thought it is a waste of time and regret. They all believe that this special experience makes them different, compared with others (King, 2011). 
Role conflict theory tells that gap year is considered as a way of gaining advantage by young people and organizations (Brown, 2003). This theory assumes that the recent changes in the labor market makes it more difficult for graduates to find a job (Heath,2007). The social interaction framework shows how young people can put their travel stories as a "device" to control the performance in the specific situation (such as job interviews), especially the establishment of the characters that can enhance their employability (King, 2011).

\subsection{The Attitudes of Employers towards Gap Years}

Employers tend to employ job seekers who participated in gap year practice. It has been confirmed that certain soft skills (interpersonal skills, communication and handling skills, etc.) and survival skills (leadership, communication and self-discipline are more valued by employers. A survey by site gapyear.com in 2011indicates that $63 \%$ of the human resources managers in the UK believe that participating in gap year travel, volunteer work or learning job skills help individuals perform better. On the other hand, students participated in gap year are more mature, independent, attentive and creative than other graduates. These qualities are more valued by the human resources department of the enterprise. General speaking, it is difficult for employers to identify these soft skills. And when young people work, employers are reluctant to support the development of these skills(Jones, 2004).

\section{Conclusions}

At present, the researches in the field of gap years are limited in number and size, and most of the studies are from England, Australia, America, Canada and other developing countries in South America and Africa in recent years. Although in recent years some scholars in China have started to pay attention to researches in this area, but academic articles on this topic is rare. Liu (2013) discussed the gap from the empirical perspective, but he did not consider the characteristics of the participants in China. Wu (2015) uses qualitative research methods to analyze the gap year practitioners in China from the perspective of tourism. But in general, the number of years of research on China interval under the situation of too little, therefore, the researchers should pay more attention to the local situation Chinese gap years, and Chinese practitioners features and empirical research, obtained valuable and worthy of reference data.

Most research on gap year focus on the practice during the transition from high school to college. Nowadays an increasing number of adults participated in gap year experience in other career stages, which was ignored by current scholars. Heath (2007) proposed that more attention should be paid on the gap year practice of individuals at the age between 20 and 30 years. Study on the practitioners of other age can further enrich the understanding of the concept of the year at present. Especially in China, more and more research on gap year should focus on the participants in other career stages, such as analysis of their motivation to turnover and participate in gap year, the benefits of gap year practice, the difference between these participants and other professionals, whether it is beneficial to their future development and the influence of gap year on the organizations that they work.

\section{Reference}

[1] Brown P, Hesketh A, Wiliams S. Employability in a Knowledge-driven Economy [J]. Journal of Education \& Work, 2003, 16(2): 107-26.

[2] Coetzee M, Bester S. The Possible Value of a Gap Year: A Case Study [J]. South African Universities Vice Chancellors Association, 2010, 23(3): 608-623.

[3] Cremin C. Living and Really Living: The Gap Year and the Commodification of the Contingent [J]. 2007.

[4] Gaskin K. What young people want from volunteering [J]. 1998. 
[5] Heath S. Widening the Gap: Pre-University Gap Years and the 'Economy of Experience' [J]. British Journal of Sociology of Education, 2007, 28(1): 89-103.

[6] Holmlund B, Liu Q, Skans O N. Mind the gap? Estimating the effects of postponing higher education [J]. Oxford Economic Papers, 2008, 60(4): 683-710.

[7] Johan N. Gap Year Travel: Youth Transition or Youth Transformation? [M]. 2009.

[8] Jones A. Review of Gap Year Provision [J]. 2004.

[9] King A. Minding the gap? Young people's accounts of taking a Gap Year as a form of identity work in higher education [J]. Journal of Youth Studies, 2011, 14(3): 341-357.

[10] Lyons K, Hanley J, Wearing S, et al. Gap year volunteer tourism: Myths of Global Citizenship? [J]. Annals of Tourism Research, 2012, 39(1): 361-78.

[11] Pearce P. 'Gap Year' in China: views from the participants and implications for the future [J]. Current Issues in Tourism, 2015, 18(2): 1-17.

[12] Simpson K. Dropping Out or Signing Up? The Professionalisation of Youth Travel [J]. Antipode, 2005, 37(3): 447-469.

[13] Snee H. Doing something 'worthwhile': intersubjectivity and morality in gap year narratives [J]. Sociological Review, 2015, 62(4): 843-61. 